\title{
Educação Financeira: APRENDIZAGEM DE PROGRESSÕES GEOMÉTRICAS APLICADAS AOS JUROS COMPOSTOS NA PERSPECTIVA DA EDUCAÇÃO MATEMÁTICA CRÍTICA $^{1}$
}

\author{
FINANCIAL EDUCATION: LEARNING GEOMETRIC PROGRESSION APPLIED \\ TO COMPOUND INTEREST IN THE PERSPECTIVE OF CRITICAL \\ MATHEMATICAL EDUCATION
}

DOI: http://dx.doi.org/10.23926/RPD.2526-2149.2020.v5.n1.p45-64.id607

\section{Martielle Soledade Souza Santos \\ Mestre em Educação \\ Matemática (UESC) \\ Professora da Rede \\ Particular de Ensino. martielle2012@gmail.com}

\section{Alfredo Dib Nour \\ Doutor em Educação \\ (UCM/Espanha) \\ Professor da Universidade \\ Estadual de Santa Cruz \\ (UESC) \\ aadib@uesc.br}

${ }^{1} \mathrm{O}$ presente trabalho foi realizado com apoio da Coordenação de Aperfeiçoamento de Pessoal de Nível Superior - Brasil (CAPES) - Código de Financiamento 001.
Resumo: O presente artigo trata-se de um recorte de dissertação de mestrado em Educação Matemática. $\mathrm{O}$ problema surge da análise de duas tendências que tratamos de articular, por um lado os dados indicam eventuais falhas no aprendizado da matemática e por outro os indicadores superiores a $60 \%$ de endividamentos das famílias. O objetivo principal é analisar o desenvolvimento do conteúdo de juros compostos a partir de uma sequência de ensino, tendo como base o estudo das Progressões Geométricas (PG) a partir do movimento da Educação Financeira. O referencial teórico articula as ideias de Skovsmose, referente à Educação Matemática Crítica (EMC), que enfatiza a aprendizagem da matemática de forma política e consciente. O estudo foi aplicado com estudantes do $1^{\circ}$ ano do Ensino Médio, de uma escola na região oeste da Bahia, Brasil, em julho de 2018, com a aplicação de uma sequência de ensino. A metodologia se fundamenta na pesquisa de natureza empírica, caráter exploratório e explicativo. As análises foram organizadas em três categorias tratando-se da concepção de dinheiro, do entendimento sobre PA e PG e as propagandas. As conclusões evidenciam a necessidade de ampliação do trabalho procurando contemplar todos os elementos pertencentes à Matemática Financeira, de modo que sejam tratados criticamente.

Palavras-chave: Educação Matemática Crítica; Educação Financeira; Progressões Geométricas.

\begin{abstract}
This article is an excerpt of a master's thesis in Mathematics Education. The problem arises from the analysis of two trends that we tried to articulate, on the one hand, the data indicate possible flaws in the learning of mathematics and on the other, the indicators above $60 \%$ of household indebtedness. The main objective is to analyze the development of the content of compound interest based on a teaching sequence, based on the study of Geometric Progressions (PG) from the Financial Education movement. The theoretical framework articulates the ideas of Skovsmose, referring to Critical Mathematical Education (EMC), which emphasizes the learning of mathematics in a political and conscious way. The study was applied to students of the 1st year of high school, from a school in the western region of Bahia, Brazil, in July 2018, with the application of a teaching sequence. The methodology is based on research of an empirical nature, exploratory and explanatory. The analyzes were organized into three categories, dealing with the concept of money, understanding of PA and PG and advertisements. The conclusions show the need to expand the work, seeking to contemplate all elements belonging to Financial Mathematics, so that they are treated critically.
\end{abstract}

Keywords: Critical Mathematics Education. Financial education. Geometric progressions. 


\section{INTRODUÇÃo}

A partir da instituição do Decreto 7367 de 22 de dezembro de 2010, fica a cargo da Estratégia Nacional de Educação Financeira (ENEF), a promoção e divulgação da Educação Financeira e Previdenciária no país. Isso se relaciona a pesquisas feitas pela Centralização de Serviços dos Bancos (SERASA) em conjunto com o Comitê Nacional de Educação Financeira (CONEF), que identifica que o brasileiro tem uma cultura de não planejar gastos, ficando a mercê de possíveis fraudes, consumismo e do endividamento (BRAZIL, 2013). Além disso, segundo o Banco Central do Brasil (BRASIL, 2013) a facilidade do acesso ao consumo aliada a ausência de Educação Financeira pode ocasionar endividamento excessivo aos consumidores, aos quais, tem a diminuição de suas reservas financeiras devido ao descontrole dos gastos, das prestações com altas taxas de juros e de aquisições que apenas trazem satisfação momentânea.

Para modificar esse patamar, o movimento da Educação Financeira, promove a discussão de um cidadão consciente, de questões ambientais, sociais, econômicas, culturais que reflitam diretamente na decisão de consumo. Consolidar consumidores conscientes para, não serem manipulados através dos apelos consumistas de um estilo de vida construído artificialmente é primordial para uma visão crítica de educação. Nesse contexto, a Educação Financeira busca articular argumentos para superar a persuasão, motivando aprendizados relacionados à administração do dinheiro como possibilidade de se realizar sonhos de curto, médio e longos prazos, estabelecendo uma relação proativa que enfatiza o investimento ou financiamento calculado e justo, prevenindo a ocorrência de hábitos de consumo por impulso ou desnecessários e assim um possível endividamento.

A utilização da Educação Financeira na vida cotidiana envolve o raciocínio e o emocional, de forma a traçar objetivos eficazes para alcançar metas de consumo. Dessa forma torna-se possível adquirir vantagens através da negociação, focalizar na busca da realização de sonhos e não comprometer a renda com excessos desnecessários (BRAZIL, 2013; BRASIL, 2013), de modo que, seja possível conseguir alcançar suas metas, a partir da reflexão mediante a compra, e para alcançar o sonho. O papel da Educação Financeira é ensinar a refletir acerca de situações que envolvem o dinheiro. Educar para conseguir atingir uma consciência que mobilize pensamentos críticos para sua vida financeira, pois "conhecimento pode ser expresso de diferentes maneiras, não apenas de modo explicitamente verbal, mas também inteiramente, em modos de agir" (SKOVSMOSE, 2014, p. 12), consolidando o pagamento das contas, tendo uma vida focada ao bem-estar pessoal, não no consumo por prazer, mas na realização de um 
sonho: a viagem esperada, a compra de algum produto, usufruir de um serviço especial, um imóvel, ou seja, a conquista.

Saraiva (2017, p. 163) afirma que o "sucesso passa por uma vida com metas a serem cumpridas por meio de um planejamento financeiro; ou seja, uma vida que se distancia do consumo exacerbado e por impulso". Deste fato, o consumidor que tem como meta o planejamento financeiro, procura lidar de forma consciente com incômodos causados pelas dívidas e a falta de recursos, para realizar o que se deseja.

No contexto do Ensino Médio, a Base Nacional Comum Curricular - BNCC - (BRASIL, 2018) enfatiza que, temas contemporâneos, como a educação para o consumo, Educação Financeira e Fiscal, devem ser tratados de forma transversal e integradora. Nessa direção, tornase necessário mostrar aos estudantes da Educação Básica, a importância de ter Educação Financeira para entender os sistemas econômicos assim como aprender o conteúdo de Matemática contextualizado. Nessa perspectiva, atingindo dois pontos cruciais: a aprendizagem para o consumo e a construção da cidadania; e a aplicação da matemática na vida cotidiana.

Nesse ensejo, procuramos evidenciar à temática através do conteúdo de Progressões Geométricas (PG) aplicadas no contexto dos juros compostos, de forma que ela não seja abordada de maneira cansativa e enfadonha, mas atribuindo-lhe significação a partir da vida para o consumo. Dessa forma, torna-se possível que os estudantes possam atuar com autonomia, pois aprenderam no ambiente escolar a mobilizar conhecimentos para a construção da cidadania crítica e para continuidade dos estudos (BRASIL, 2018). Tal trabalho torna-se relevante, visto que, os juros compostos estão inseridos em diversos contextos da nossa sociedade, devido ao seu caráter capitalista e a grande incidência de utilização de recursos financeiros para compra, venda, parcelamentos e investimentos.

Este artigo é um recorte de dissertação de mestrado em Educação Matemática. O objetivo se fundamenta em analisar uma sequência de ensino sobre Educação Financeira aplicada a juros compostos, com base nas Progressões Geométricas (PG). Tal sequência traz o ambiente de aprendizagem da Educação Financeira, proporcionando que os estudantes façam investigações sobre a concepção do dinheiro, propagandas e a PG aplicada aos juros. Para possibilitar a construção do ambiente da Educação Financeira, utilizamos a Educação Matemática Crítica (EMC) como articuladora de momentos de discussão e construção da consciência financeira por parte dos estudantes. Esse trabalho foi desenvolvido com estudantes do $1^{\circ}$ ano do Ensino Médio de uma escola localizada na região oeste da Bahia. 


\section{EdUCAÇÃO PARA A CIDADANIA CRÍTICA EM SALA DE AULA}

No decorrer da consolidação da escola como objeto reestruturador da sociedade (GODOY, 2015), em que o ensino muitas vezes, era focado em fortalecer os ideais dominantes. Foi possível construir teorias consideradas críticas, que receberam influências voltadas à valorização das multiculturas, o gênero e o significado do conteúdo ensinado, sobretudo no que tange a Matemática. Nesse momento a necessidade de valorização da classe trabalhadora, assim como suas carências ganha espaço, a ponto de ser questionado em que caminhos o ensino tem enveredado e até que ponto este contribui para a construção de uma sociedade justa e igualitária. Skovsmose (2014, p. 14) enfatiza duas vertentes, as quais relacionaram as maneiras com que tratamos a Matemática. Para ele,

[...] há a educação matemática das escolas, em que o ensino fica a cargo dos professores e a aprendizagem fica a cargo dos alunos. E há a educação matemática fora da escola. Ensina-se e aprende-se matemática no trabalho e em muitas atividades diárias: no comércio, nos bancos, no noticiário etc.

Segundo o autor, dentro da Educação Matemática das escolas existe uma discrepância entre o ensino e a realidade, os professores apresentam o conteúdo e os estudantes se internalizam, sem uma preocupação com a adaptação a realidade, podendo ser passível ao esquecimento, pois não trouxe significado. No que tange ao ensino, não há uma preocupação em provocar discussões com o conteúdo, que motivem a participar da aula. Ao contrário desta, a Educação Matemática fora da escola evidencia fatos relacionados à vida do estudante a partir de discussões de temas voltados para o que acontece no mundo, na cidade, nas ruas, ou em manchetes de jornais. Desse modo, o Ensino da Matemática não fica preso apenas a uma explicação científica, mas as suas aplicações.

No momento em que o professor evidencia as relações entre a Matemática e a sociedade, a partir do conteúdo proposto, abre um leque de possibilidades de uma formação crítica. Pois, formar um consumidor consciente e atuante, é de extrema importância para a vida do estudante, tendo em vista a complexidade das informações apresentadas no mundo do consumo, endividamento ou possíveis golpes. Deste fato, identificamos a importância de uma educação para a emancipação do estudante. Skovsmose (2001, p. 101) enfatiza que,

[...] para que a educação, tanto como prática quanto como pesquisa, seja crítica, ela deve discutir condições básicas para a obtenção do conhecimento, deve estar a par dos problemas sociais, das desigualdades, da supressão etc., e deve tentar fazer da educação uma força social progressivamente ativa.

Refletindo os fatos mencionados por Skovsmose, percebe-se que, uma educação que se diz crítica procura situar e melhorar a vida do cidadão, entendendo a relevância do 
conhecimento apresentado, a formação atuante em sociedade, e principalmente as relações de poder inerentes ao conhecimento matemático. Nessa perspectiva, a prática do professor emana ideologias, transmitidas através do diálogo em sala de aula. Motivar a criticidade na abordagem de temas relevantes aos estudantes traz a atenção para as discussões, muitas vezes veladas pelas relações de poder, os levando a absorver de maneira ingênua e acrítica a temática envolvida e até mesmo o conteúdo proposto. Ler criticamente informações pressupõe o entendimento de números e cálculos, além das diversas incertezas às quais a matemática está inserida (SKOVSMOSE, 2014).

\section{O conteúdo de Progressões Geométricas (PG) no contexto da Educação FINANCEIRA}

Conforme a Base Nacional Comum Curricular - BNCC (BRASIL, 2018) uma de suas competências gerais comuns a todos os currículos, enfatiza a necessidade de argumentar com base em dados confiáveis, visando formular, negociar, defender ideias em conformidade com os direitos humanos, consciência socioambiental e consumo responsável. Tais competências objetivam a formação de um indivíduo autônomo para a sociedade. E esse trabalho, varia de acordo com as ideologias as quais o professor interage com os estudantes em meio à abordagem do conteúdo, o que faz com que o conteúdo possa ser apresentado de forma problematizada ou apenas na forma definição-conteúdo-exercício (SKOVSMOSE, 2000).

Destarte, a BNCC também enfatiza a autonomia dos sistemas, redes de ensino e das escolas, a incorporação de propostas pedagógicas e currículos que trabalhem temas transversais com grande importância em escala global, como é o caso da Educação Financeira (BRASIL, 2018). Nesse sentido, dar significado ao conteúdo e formar consumidores para a construção de uma consciência financeira crítica nunca foi tão importante. Pois, lidar com o dinheiro necessita de planejamento, negociação e cuidar do meio ambiente, tendo em vista que, a todo o momento, tomamos decisões, que podem mudar a nossa história. Todos estes fatos mencionados fazem referência a um ensino problematizado, que apresente o conteúdo e sua interação no mundo como um todo, abrangendo o contexto de cenários ${ }^{1}$ reais e semirreais.

No que tange a apresentação do conteúdo de juros, percebe-se que este é um dos temas que podem ser norteadores, para o trabalho com Progressões Geométricas (PG). Isso porque, existe a possibilidade de associação e integração com o contexto proporcionado pela Educação

\footnotetext{
${ }^{1}$ Conforme Skovsmose (2000) os Cenários para Investigação são ambientes que dão suporte ao trabalho de investigação na sala de aula.
} 
Financeira, neste aspecto, podendo tornar o conteúdo mais significativo, motivando atitudes de consumidores conscientes, formando-os para a vida como um todo. Nesse sentido, o aluno poderá compreender regularidades, influências de taxas, propriedades, identificação de lei de formação, de modo que, o professor possa acompanha-lo de maneira ativa (BRASIL, 2007).

Ao trabalhar com PG na perspectiva da Educação Financeira, enfatizamos o ambiente de investigação, que consiste na aplicação e discussão de situações em contextos reais e semirreais que sirvam para a formação de um consumidor consciente, tanto no que concerne ao desenvolvimento de cálculos de juros compostos (gestão do conteúdo), como na própria consciência financeira para lidar com planejamentos, consumo, imprevistos, entre outros. Nesse contexto, a intenção passa por explorar o ambiente da Educação Financeira para dar significado ao estudo de PG.

Para um melhor entendimento dessa articulação com a definição de PG proposto por Iezzi (1977, p. 5), temos:

Chama-se Progressão Geométrica (PG) uma sequência dada pela seguinte fórmula de recorrência:

$$
\left\{\begin{array}{c}
a_{1}=a \\
a_{n}=a_{n-1} \cdot q, \forall n \in \mathbb{N}, n \geq 2
\end{array}\right.
$$

Onde $a$ e $q$ são números reais dados.

Assim, para Iezzi (1977, p. 18; 2004, p. 24) uma "PG é uma sequência em que cada termo, a partir do segundo, é o produto do anterior com uma constante $q$ dada".

Desse modo, para o entendimento do excerto apresentado anteriormente, torna-se necessário conhecimento da linguagem matemática, muitas vezes desconhecida pelos alunos, pois todo o trabalho com a descoberta dos termos da progressão irá se encadear em uma equação. Em vista disso, ressalta-se que a importância da definição para a aprendizagem de um dado conteúdo matemático, não somente sendo compreendida de definições e símbolos da área, mas repleta de significado e aplicações, procurando a aceitação do convite para investigar, através de abordagens mais significativas.

Segundo Lima et al (2006) o conhecimento isolado de fórmulas pode atrapalhar os alunos quando a progressão inicia em $a_{0}$. Deste fato torna-se mais eficiente saber que é necessário multiplicar por $q$ sempre que for avançar um termo, encontrando a fórmula por consequência. Entendendo a definição conforme apresentado por Iezzi $(1977$; 2004) que a PG é uma sequência, em que cada termo a partir do segundo é multiplicado por uma constante q, temos: 


$$
\begin{gathered}
a_{1}=a \\
a_{2}=a \cdot q=a_{1} \cdot q \\
a_{3}=a \cdot q \cdot q=a_{2} \cdot q=a \cdot q^{2} \\
\ldots \\
a_{n}=a_{n-1} \cdot q=a_{1} \cdot q^{n-1}
\end{gathered}
$$

Como apresentado por Lima et al (2006), o entendimento da definição leva a encontrar a fórmula por consequência. Nesse ensejo, Lima et at (2006, p.49) enfatiza que "é absurdo, mas infelizmente é comum, ensinar progressões geométricas e não relacioná-las à ideia de taxa de crescimento". Consequentemente, reforça a necessidade de contextualização do tema com a Educação Financeira, principalmente no que tange ao ensino de juros compostos. Pois trata-se de uma capitalização em que é possível trabalhar temas na sala de aula como empréstimos e financiamentos, inclusive as taxas que podem enfatizar rentabilidade ou prejuízos.

Como proposto por Iezzi (1977; 2004) para a PG, Piccini (2011, p. 15) destaca que "no regime de juros compostos, os juros de cada período são obtidos pela aplicação da taxa de juros $i$, sobre o capital aplicado no início do período de capitalização”. Para entender melhor esse conceito o autor apresenta uma demonstração para os juros compostos, em que:

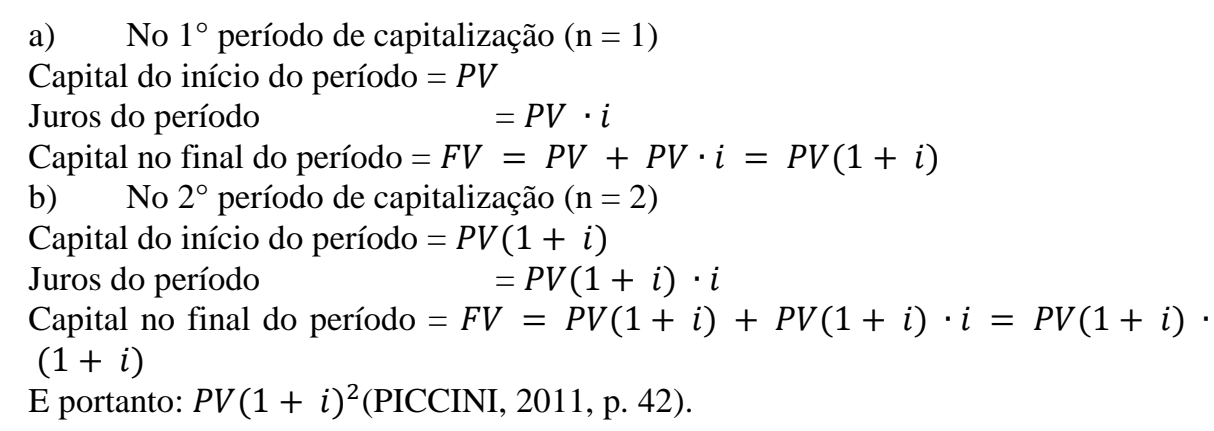

Através do excerto é possível perceber que no $3^{\circ}$ período de capitalização será expresso por $F V=P V(1+i)^{3}$, em que no enésimo período teremos uma configuração padrão equivalente a $F V=P V(1+i)^{n}$, (PICCINI, 2011).

Isso indica que, ao se aplicar um capital (PV), a uma taxa $i$, durante um tempo determinado $(n)$, observa-se que inicialmente o nosso capital será apenas multiplicado pela taxa, a qual identifica o rendimento da operação, tendo em vista que temos apenas um período de capitalização. Entretanto, com o passar do tempo, na enésima capitalização, ao qual a taxa e o capital foram aplicados, percebendo a obtenção da fórmula $F V=P V(1+i)^{n}$.

Os juros de fato estão inseridos em diversos contextos da nossa vida, uma fatura atrasada, um investimento no banco, compra parcelada entre outros, fazem com que seja 
necessário ter conhecimento desta temática. Em vista disso, a intenção da nossa proposta está em relacionar o cálculo dos juros compostos com as Progressões Geométricas. A partir disso, encontrar o valor de um $a_{n}$ (um montante futuro), como mostra a situação proposta acima, teremos que, $a_{n-1}$ será identificado como o capital inicial, $q$ a razão (a taxa) de crescimento ou decrescimento $\left(a_{n}=a_{n-1} \cdot q\right)$. Deste modo, temos a mesma configuração inicial proposta para a fórmula do cálculo dos juros compostos $\left(F V=P V(1+i)^{n}\right)$. A partir dessa relação é possível dar significado ao conteúdo de PG na perspectiva dos juros. Além disso, a PG também tem outras aplicações como as funções exponenciais, entretanto este tema não será enfatizado neste artigo.

\section{Metodologia da Pesquisa}

A metodologia deste artigo se fundamenta na pesquisa de natureza empírica de caráter exploratório e explicativo, com levantamento bibliográfico e de dados com uma sequência de ensino e análise qualitativa. A sequência apresentada nessa secção articula o estudo da Educação Financeira com a Matemática numa perspectiva crítica do ensino. Composta por três atividades, aplicadas no $1^{\circ}$ ano do Ensino Médio, ela foi aprovada pelo Comitê de Ética e Pesquisa (CEP).

A duração total consiste em duas aulas de 50 minutos (100 minutos). Participaram da pesquisa cinco estudantes (A, B, J, M, R), conforme a aceitação e assinatura, do Termo de Consentimento Livre e Esclarecido (TCLE), pelos pais e/ou responsáveis, e do Termo de Assentimento Livre Esclarecido (TALE), feito pelos respectivos participantes. As respostas foram selecionadas conforme a relevância e entendimento a partir das transcrições das gravações de áudio, ocorridas durante o momento de intervenção. A aplicação ocorreu no mês de julho de 2018, com uma turma do $1^{\circ}$ ano do Ensino Médio de uma escola pública estadual do oeste da Bahia. Os participantes da pesquisa tinham em torno de 14 a 17 anos de idade.

Para iniciar a pesquisa, os estudantes foram convidados a cantar a música Pecado Capitais de Paulinho da Viola, que enfatiza a dificuldade de se lidar com o dinheiro. Em seguida, deu-se início a uma discussão sobre o tema e evidenciando aspectos que se relacionam ao dinheiro ao tempo, a influência da sociedade, ser vendaval e solução, o dinheiro para os bancos, a poupança e os empréstimos financeiros/financiamentos.

Após esse momento de discussão, iniciou-se a atividade. A princípio apresentamos aos estudantes a seguinte história em quadrinhos. A Figura 1 abaixo apresenta a situação. 
Figura 1 - Investimentos Financeiros
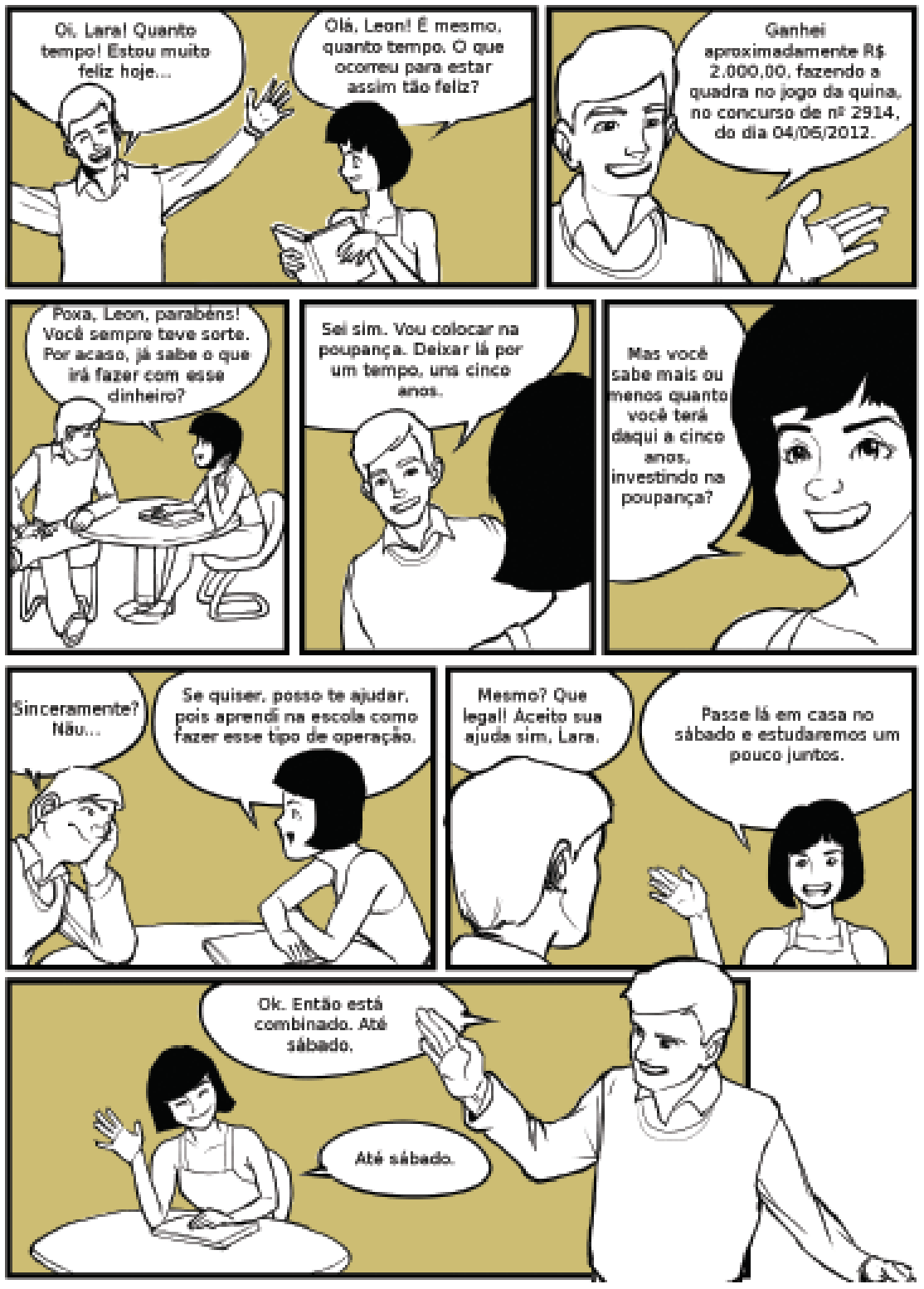

Fonte: Fundação CECIERJ (2016, p. 7)

A situação acima evidencia um rapaz que acaba de ganhar aproximadamente dois mil reais $(\mathrm{R} \$ 2.000,00)$ no jogo da loteria. O objetivo inicial era entender como ocorre o rendimento, através da capitalização em juros compostos, feita por depósito na poupança, no período de cinco anos. Pois, a situação mostra que o ganhador do dinheiro não sabia qual a quantia que receberia ao final deste período de tempo. A partir dessa situação a atividade um consiste em:

Quadro 1 - Primeira atividade

A partir do entendimento de como funciona a poupança vamos fazer a projeção dos valores que Leon ganharia por ano. Construa uma tabela de dados contendo os dados variando de 6 em 6 meses. 
Com essa atividade, retomou-se a ideia das taxas aplicadas na poupança (para exemplo: 0,5\% ao mês). Além disso, os estudantes puderam analisar nas tabelas os conceitos de Progressão Geométrica (PG), entendendo as diferenças existentes entre os juros simples e compostos, estabelecendo uma comparação, de quanto Leon ganharia aplicando nesses dois tipos de capitalização. A partir disso, foi possível encontrar o termo geral da PG, e analisar situações com valores de $n$ (tempo em meses) diferenciados, o qual seria nossas projeções dos valores.

A segunda atividade é apresentada no Quadro 2. Salienta-se que os alunos necessitaram utilizar a calculadora no que tange a utilização de expoentes de potência acima de 5, como o exemplo proposto na atividade.

Quadro 2 - Segunda atividade

E se Leon pegasse um empréstimo com esse valor e a taxa de $\mathrm{i}=2,8 \%$ mensais. Quanto Leon pagaria ao banco? Construa uma tabela para o tempo de 2 anos. Construa uma tabela com os dados variando de 6 em 6 meses.

Fonte: Autores

Evidencia-se a diferença entre a taxa para a aplicação em um investimento e a taxa de empréstimos, levando em consideração a lucratividade dos bancos ao trabalhar com o dinheiro dos poupadores. Para isso, é necessário compreender que a taxa e o tempo podem ser diários, mensais, trimestrais, entre outros, o que mostra a necessidade de atenção do consumidor ao adquiri-las. Além disso, é preciso ainda compreender a variação dos juros em que será pago por período e compará-lo ao total, no final do empréstimo, fazendo uma relação entre o valor emprestado e pago ao banco.

A partir dessa comparação é possível fazer uma reflexão: "se tivesse poupado esse dinheiro, durante esse período, valeria mais a pena do que ter feito o empréstimo pagando mais dinheiro para o banco? ". No tocante a problemática, torna-se importante evidenciar o tempo e a necessidade de aquisição de produtos e serviços de maneira imediata, como um fator prejudicial quando se trata de poupar e investir.

A terceira atividade propõe estimular a criticidade em meio a influências do mundo do consumo. Foram apresentadas três propagandas, as quais, os estudantes juntamente com o professor fizeram análises e comentários a partir destas. A turma foi dividida em dois grupos os compradores e os vendedores. Os alunos compradores, afirmaria, o porquê compraria ou não, esse produto, enquanto que os vendedores teria que convencer o comprador em potencial. 
No final, a professora sistematiza o conteúdo relacionado à Educação Financeira, o excesso de consumo como fator prejudicial para o meio ambiente.

Após enfatizar o estudo do valor do dinheiro no tempo, desenvolve-se a criticidade mediante ao poder de persuasão da propaganda para a compra de um produto ou aquisição de um serviço. Para isso, destacaram-se três propagandas para serem comentadas durante a aula: um smartfone, uma sandália infantil e um posto de combustível.

A propaganda de smartfone traz a ideia de que tudo o que emociona não pode esperar, nesse sentido, evidencia-se encontros, ligações, filmagens feitas por dispositivos móveis (celulares), enfatizando que não podemos perder tempo, temos que adquiri-lo ou deixaremos de registrar momentos importantes da nossa vida. Nesse sentido, o que se espera é que os estudantes percebam que é possível comparar preços antes da aquisição de um produto, e que a felicidade não está subordinada a aquisição do produto. Além disso, o contexto da mídia social em meio à necessidade de "guardar momentos", questionando assim: para que, esses momentos, precisam ser registrados? Para serem compartilhados? Ou apenas relembrados?

A propaganda da sandália infantil procura dar dicas para as crianças de como pedir de presente aos pais, como exemplo da sandália, enfatizando a necessidade de obedecer e não fazer travessuras para conseguir tal proeza, além disso, ao final do vídeo à criança pede o presente cantando. A visão crítica que se pretende que seja adquirida, com esse vídeo, relaciona-se com a necessidade de adquirir um produto, capacidade de persuasão da criança, sendo o ideal combinar a compra ou incentivar a guardar dinheiro para a conquista de um sonho.

A propaganda do posto de gasolina evidencia a música "Livre estou" do filme Frozen: uma aventura congelante, na qual a partir do momento em que o consumidor abastece no posto de combustível, obtém-se um caminho livre, sem eventuais imprevistos, ou seja, o consumidor ficará tranquilo. Deste modo, torna-se interessante discutir que a partir do momento em que o motorista mantém o carro organizado, e abastece em posto com gasolina de qualidade, é possível prevenir que imprevistos aconteçam.

\section{AnÁlise}

A tabulação de dados foi desenvolvida incorporando quatro etapas: a) transcrição dos áudios, coletadas durante a intervenção com a sequência de ensino; b) seleção de momentos para serem discutidos; c) construção de categorias de análise; e d) cruzamento dos dados com pesquisas desenvolvidas na área. As categorias de análise foram denominadas Educação Financeira: concepções dos estudantes acerca do dinheiro; ao qual vai evidenciar aspirações 
dos estudantes motivadas pela música Pecado Capital. A segunda categoria Educação Financeira: concepção dos estudantes quanto ao trabalho com PG aplicada aos juros compostos; que articula o conhecimento matemático aplicado a situações financeiras. A terceira categoria Educação Financeira: concepção dos estudantes acerca das propagandas; que expressem a compreensão dos alunos sobre três propagandas selecionadas para discussão.

\section{1. $1^{\text {a }}$ CATEgORIA: EdUCAÇão FinANCEIRA - CONCEPÇÕES DOS ESTUdANTES ACERCA DO DINHEIRO}

No início da aplicação da sequência, a partir da análise da letra da música, percebeu-se que a estudante $\mathbf{A}$ acredita que, o dinheiro serve para atender necessidades, e que, se não bem organizado pode ser perdido facilmente, conforme a citação: "dinheiro na mão é vendaval na mão de quem não sabe ter" (A); percebemos também que a estudante dá indícios de que é necessário saber administrar o dinheiro, caso contrário, ele pode "sumir no vendaval", o vendaval que está implícito na fala, refere-se às investidas do mercado de consumo para suprir necessidades momentâneas, para satisfação de prazeres, indo de encontro à atividade do mercado de consumo, ou seja, induzir a compra.

Baumam (2008, p. 15) enfatiza que “(...) o trabalho, por outro lado, deve ser mantido em condição impecável, pronto para atrair o olhar de potenciais compradores, conseguir a aprovação destes e aliciá-los a comprar o que estão vendo". Nesse sentido, o mercado planeja, trabalha e investe para apresentar algo belo e desejável ao consumidor que não tem organizado seu planejamento pessoal, a fim de que ele tome decisões sem analisar as consequências de um possível endividamento.

Além disso, conforme o contexto da música a estudante $\mathbf{B}$ acredita que o dinheiro quando não bem administrado acaba "[o dinheiro, quando mal empregado, pode acabar] trazendo briga" (B); essas desavenças motivadas pelo tratamento que o consumidor faz com relação ao dinheiro, como sendo um recurso imprescindível para sua vida, muitas vezes ligado à satisfação de felicidade. A estudante $\mathbf{J}$ percebeu que a letra da música relaciona diversos conceitos, como o consumo, o prazer associado à compra para ter um bem-estar físico e emocional, a discórdia ocasionada pelo estímulo à competição proposto pela sociedade capitalista, e a formação com consumidor consciente, conforme a citação "esta música trouxe muitos conceitos estudados, o consumo, a necessidade do bem-estar, a discórdia, o saber ser consumidor consciente" (J). Nesse sentido, a fala dessa estudante sintetiza a função de sujeito autônomo para com o dinheiro em nossa vida, entendendo que é preciso consumir com 
consciência e utilizar o dinheiro como fonte de bem-estar para a vida. Para isso, torna-se importante determinar metas e gerenciar as contas, conforme salienta Saraiva (2017). Além disso, a estudante evidencia a retomada dos conceitos de consumo, consumismo, bem-estar físico e emocional, evidenciados durante a aplicação da sequência.

Deste fato, o papel da Educação Matemática, principalmente no que tange ao dinheiro torna-se de grande importância, não sendo apenas fórmulas ou métodos de resolução de problemas, más que estes estejam aplicados a contextos reais e semirreais aos quais os estudantes estejam inseridos (SKOVSMOSE, 2000; 2001; 2014).

\section{2. $2^{\circ}$ CATEGORIA: EDUCAÇÃO FINANCEIRA - CONCEPÇÃO DOS ESTUDANTES QUANTO AO TRABALHO COM PG APLICADA AOS JUROS COMPOSTOS}

Dentro do ambiente de aprendizagem da Educação Financeira, além das discussões acerca do comportamento motivado pelas influências da sociedade capitalista, também iremos ressaltar as atividades desenvolvidas por alguns estudantes, com possibilidade de aplicação em contextos reais, conforme a discussão que estas podem motivar. A partir do entendimento da configuração do trabalho realizado, destacamos a resolução da primeira atividade, feita pelo estudante M, através da Figura 3.

Figura 2 - Atividade 1 do Estudante M

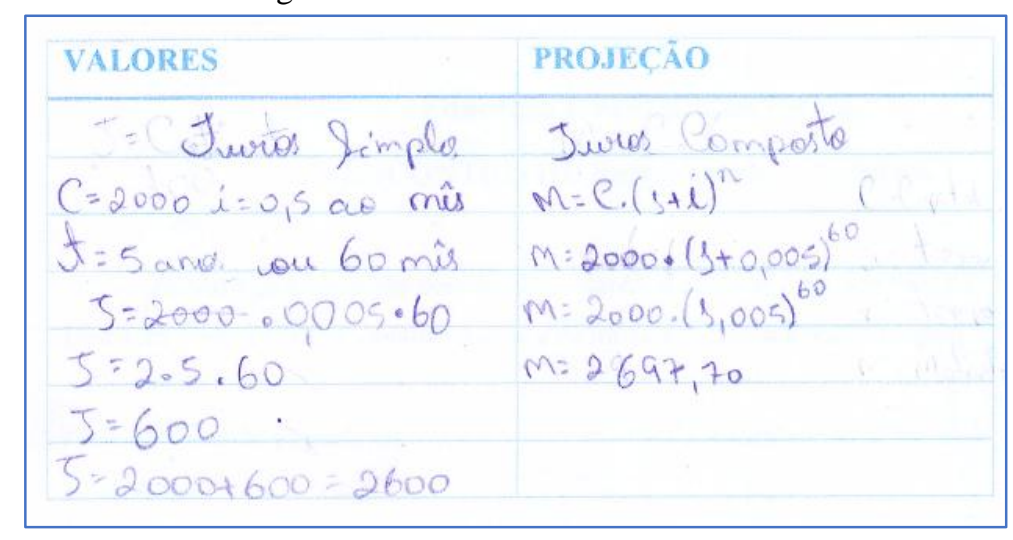

Fonte: Protocolo dos alunos.

De um modo geral, os alunos optaram por fazer a comparação da aplicação de Leon com os juros simples, estudados no encontro anterior através das Progressões Aritméticas (PA) e os juros compostos, aplicados como (PG). Nesse encontro, ao invés de fazer a comparação em meses, os alunos, evidenciaram apenas o resultado final das duas formas de capitalização, e suas discrepâncias entre os valores. Torna-se possível perceber a conversão do tempo em meses, e os cálculos desenvolvidos de maneira adequada, levando em consideração a utilização da calculadora, conforme Lima et al (2006, p. 43) argumentam que as "calculadoras são 
indispensáveis para a resolução de quase todos os problemas de progressões geométricas da vida real". Desse modo, além de facilitar o cálculo e fortalecer o entendimento do problema, foi possível que os estudantes percebessem que a aplicação com os juros compostos se torna mais rentável $\mathrm{R} \$ 97,70$ a mais, que nos juros simples.

No que tange a variação de 6 meses, o estudante $\mathbf{R}$ desenvolveu o seguinte cálculo apresentado na Figura 3.

Figura 3 - Atividade 1 do Estudante R

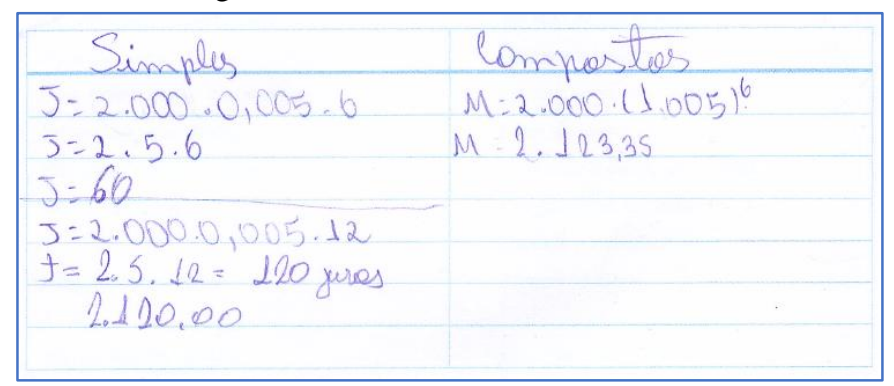

Fonte: Protocolo dos alunos.

Percebe-se que, estes estudantes entenderam o conceito e desenvolveram corretamente o cálculo de projeção para 12 meses, se o capital de Leon fosse aplicado a juros simples. Esse tipo de proposta pode ser feito visando comparar a rentabilidade dos tipos de capitalização. Além disso, nessa questão compreende-se que, alguns alunos preferem usar os juros simples. Acredita-se que, esse fato tenha ocorrido, devido a melhor compreensão do tema, quando comparado aos juros compostos. Outros erraram ambos os casos, principalmente multiplicação de números decimais. Entretanto o fato de errar a questão por conta de conteúdos anteriores reforça a necessidade de o professor estar sempre retomando alguns conhecimentos para consolidar outros, "inserido num permanente movimento de procura, faz e refaz constantemente o seu saber. E é por isso que todo saber novo se gera num saber que passou a ser velho, o qual, anteriormente, gerando-se num outro saber que também se tornara velho, se havia instalado como novo" (FREIRE, 1977, p.47).

A Figura 4 apresenta a forma como a estudante $\mathbf{J}$ desenvolveu a segunda atividade.

Figura 4 - Atividade 2 do Estudante J

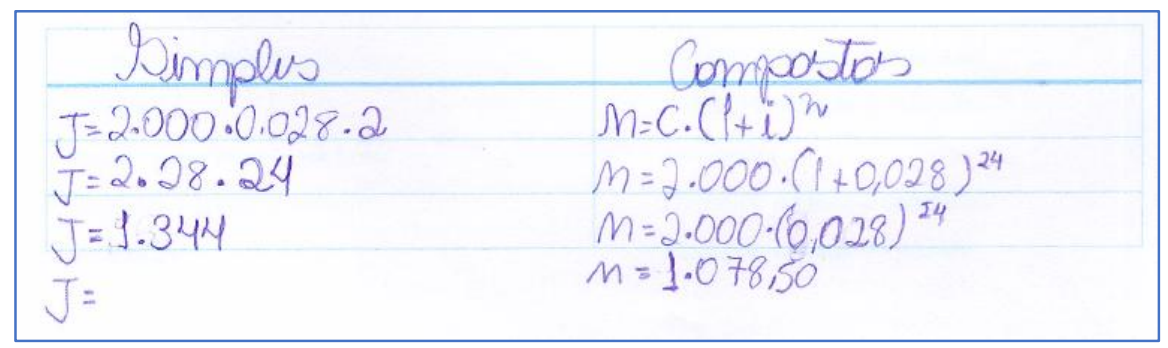

Fonte: Protocolo dos alunos 
Observa-se na apresentação da resposta que inicialmente o estudante coloca um 2, já que a questão aponta o tempo 2 anos. Posteriormente, o estudante substitui o 2 por 24, por conta da taxa que se encontra mensal, fazendo assim a relação entre meses e ano. A partir dessa constatação, ele desenvolve o cálculo dos juros simples de forma correta, inclusive a multiplicação com decimais. Nos juros compostos ocorreu um erro comum, isso por que os estudantes elevaram somente a taxa $(2,8 \%)$ a 24 (número de meses), desse modo o montante foi calculado incorretamente. $\mathrm{O}$ valor correto seria $M=3.880,29$, essa ideia poderia ser percebida a partir da rentabilidade, sendo os juros compostos mais rentáveis que os simples a partir do primeiro mês e ao considerar taxas diárias. Além disso, é possível ressaltar que o uso da calculadora, conforme Lima et al (2006) salienta, não impediu que os estudantes errassem o cálculo na atividade, pois esse erro parte da compreensão dos estudantes, não da utilização de uma ferramenta de facilitar cálculos matemáticos.

\subsection{3 ${ }^{a}$ CAtegoria: EduCaÇão FinanCeira - CONCEPÇão dos ESTUdanteS ACERCA DAS PROPAGANDAS}

Conforme Bauman (2008) a sociedade capitalista é a única a qual tem como valor supremo prometer uma vida feliz. A partir desse fato, todos os produtos ou serviços surgem para tornar essa felicidade efetiva, mesmo que momentânea, diante desse fato, inicia-se a busca contínua, muitas vezes motivada pelos impulsos, de comprar, gastar, juntar e se sentir bem através dessas ações, sem ao menos refletir sobre elas. Nesse sentido, “(...) a educação não pode apenas representar uma adaptação às prioridades políticas e econômicas (quaisquer que sejam); a educação deve engajar-se no processo político, incluindo uma preocupação com a democracia” (SKOVSMOSE, 2014, p. 19). Deste fato, uma economia considerada sólida necessita estar estável no que tange ao consumo, sendo que, tanto o excesso, como o declínio pode gerar graves problemas principalmente nos preços dos produtos, atacando diretamente o consumidor. Por isso, torna-se importante consumir com consciência, estabelecendo reflexões da necessidade do produto e identificando a capacidade de persuasão das propagandas. Acerca deste tema salientam-se as interpretações feitas pelos estudantes, no primeiro momento, quanto a uma operadora de telefonia.

O estudante $\mathbf{R}$ foi perceptivo, no que tange a apresentação da propaganda, conforme a citação "é uma propaganda da [operadora X]" (R); tendo em vista que, a publicidade traz a intenção de que ela possa encurtar distâncias e que momentos devem ser registrados. E um ponto forte apresentado nessa propaganda são elementos da vida de uma família, desde o 
namoro a distância, até o momento em que a filha consegue andar de bicicleta, procurando evidenciar o foco que é registrar momentos.

Além desse estudante, outros se manifestaram, mas não tinham percebido a marca por trás da publicidade. Ao final do comercial, foi perguntado aos estudantes, qual seria a intenção da propaganda. $\mathrm{O}$ estudante $\mathrm{M}$ evidencia que, "Tem que ter ela [a câmera do smartfone] para ser feliz" (M); assim como o estudante $\mathbf{J}$ "se você quiser encurtar distâncias tem que usar ela [os planos da operadora telefônica; o smartfone]" (J). À vista disso expressam as ideias de Baumam (2008) acerca da felicidade promovida pela sociedade capitalista, que utiliza de diversos recursos da mídia para estampar em todos os ambientes, quais são as nossas necessidades, o que devemos comprar; fazer ou ser, para pertencer ao grupo.

A discussão da propaganda foi motivada pelas argumentações baseadas na sutileza da mensagem que busca relacionar diretamente a felicidade com o produto que a empresa vende, necessitando que o consumidor tenha visão crítica para não ser levado pelas ideologias das marcas, conforme salienta Skovsmose $(2000 ; 2001$; 2014) a respeito da matemática das ruas e a necessidade de contextualização com o mundo ao qual estamos inseridos.

A segunda propaganda se destaca por tentar influenciar dois públicos: as crianças e seus responsáveis/pais, que serão bombardeados por pedidos de compra de produtos. A cartilha de Educação Financeira para pais afirma que "a criança acredita naquilo que ouve e vê, não discrimina a fantasia da realidade. Se um produto diz que, ao ser consumido, deixará a criança mais forte ou mais bonita, ela acreditará" (BRASÍLIA, 2011, p. 48). Nesse sentido, é de extrema importância, que as crianças não fiquem exposta muito tempo a propagandas apresentadas nos diversos meios de comunicação, além disso, realizar combinados, relacionados às metas financeiras é interessante para formar um futuro cidadão crítico, no que tange ao dinheiro, a espera para a conquista, ensinando-o a ser um consumidor consciente.

O perfil da propaganda infantil procura influenciar crianças a comprar um objeto, nesse caso, uma sandália, por associa-la a uma cantora/apresentadora infantil famosa, um ícone do público infantil. Ensina ainda a como persuadir os pais para comprar o produto. Ao final da apresentação do vídeo, foi perguntado aos estudantes o que eles puderam perceber. Após retomar o vídeo, a estudante B salientou "o sapato que tem um relógio" $(\mathbf{B})$; o relógio, também se apresenta como um atrativo para a compra do produto, entretanto, a princípio os estudantes não estabeleceram a relação ícone-produto-compra, foi necessário que evidenciasse quem era o ícone da sandália. Os estudantes como um todo, "uma cantora”; A ênfase nas discussões na 
sala procurou relacionar a figura de uma cantora para o público infantil vendendo o produto para crianças.

Nesse sentido, foi evidenciado pelos estudantes, a forma que os canais de comunicação buscam sensibilizar as pessoas a adquirem seus produtos e serviços para crianças. Cook (2004) acredita que, torna-se impossível evitar o encontro de ícones ou personagens da mídia, que visam estimular o uso e consumo voltado para crianças. Pois, a influência de um personagem para fazer uma criança gostar de um produto, a ponto de querer comprá-lo, passa por toda uma lojista de uma empresa que faz a ligação entre o produto e o público que a cantora atinge. Cabe salientar se o produto que a imagem da cantora está ligada é de qualidade, podendo proporcionar aos fãs mirins conforto. Esses e outros aspectos são de grande importância ao se adquirir um produto, não somente vender a imagem da cantora através do produto, como as crianças são levadas a pensar.

Percebe-se que saber o que está por trás de um produto, a qualidade, a imagem que a propaganda passa para o consumidor, tornou-se o destaque para os estudantes que puderam se questionar até que ponto a propaganda exerce influências em suas vidas. Para concluir a atividade, foi perguntado: quais são as observações que devemos fazer ao decidir comprar um produto? Os estudantes acrescentam: "[as pessoas] precisam pesquisar os preços [dos produtos], analisar o produto...", completam "se precisa [analisar a necessidade] ou vale a pena comprar [o objeto de desejo]" (J), além disso, "observam se está em um tempo bom para comprar..." (R). Nesse sentido, os estudantes vivenciaram momentos de discussão relacionados a propagandas e os gatilhos mentais que elas proporcionam para o pensamento do consumidor.

A partir do momento em que o estudante olha as propagandas com uma visão crítica, pretende-se que estes recursos, não irão mais persuadi-lo a comprar sem necessidade, esta é uma das atividades propostas para educar com criticidade e construir um consumidor consciente, mediante as adversidades da sociedade do consumo. Estas são visões que emanam de uma educação de cunho ideológico crítico, procura emancipar os estudantes das armadinhas do mundo capitalista.

\section{CONSIDERAÇÕES FinaIS}

O objetivo desse artigo foi analisar uma sequência de ensino sobre Educação Financeira aplicada a juros compostos, tendo como base as Progressões Geométricas (PG). Tal trabalho proporcionou desenvolver a consciência crítica dos estudantes envolvidos, no que tange a 
Educação Financeira vivenciada no mercado de consumo e no próprio conteúdo de Progressões Geométricas (PG) aplicadas ao estudo de juros compostos.

Nesse trabalho tornou-se evidente que desenvolver uma aula na perspectiva crítica do conhecimento, salienta o potencial da percepção de realidades distintas inerentes em nossa sociedade. Percebeu-se que isso ocorre porque a Educação Financeira está aplicada no contexto de nossa vida como um todo. Mas esta evidência e nos alerta para uma necessidade, como a importância de atribuir significados ao conteúdo, principalmente a PG, uma progressão geométrica, em muitos casos tratada apenas a partir de exaustivas demonstrações de fórmulas. A ausência deste sentido afasta o estudante do pensamento matemático e o torna um consumidor fragilizado na sociedade consumista.

A primeira categoria denominada Educação Financeira: concepções dos estudantes acerca do dinheiro; possibilitou entender que os estudantes acreditam que é necessário saber lidar com o dinheiro, tendo em vista as investidas do mercado de consumo para a tendência de comprar sem necessidade. A educação aparece como crítica no sentido de possibilitar ao estudante um olhar crítico, acerca do que a sociedade expõe como vitrine, e essencial para a vida. De forma que o cidadão, não aja de forma mecanizada, mas sim refletindo a sua vida, contexto e o que realmente precisa.

A segunda categoria Educação Financeira: concepção dos estudantes quanto ao trabalho com PG aplicada aos juros compostos; A contextualização da PG no que concerne aos juros compostos possibilitou encarar a matemática como necessária para a vida em sociedade, entendendo a rentabilidade e a utilização dos juros compostos nos diversos momentos da vida. Visto que, torna-se importante, até mesmo para evitar possíveis fraudes, golpes os quais a sociedade consumista está propícia. Nesse sentido, a matemática, em especial os juros compostos são importantes, inclusive para refletir as taxas de investimento e financiamento do nosso país, em que os juros compostos valorizam mais o empreendedor, que o investidor.

$\mathrm{Na}$ terceira categoria Educação Financeira: concepção dos estudantes acerca das propagandas; tornou-se de extrema importância apresentar aos estudantes as intenções das propagandas, as ideias por trás da satisfação e fidelidade, que podem fazer com que o consumidor fique alienado mediante tantas opções e comerciais que indicam objetos como sendo essenciais para a vida. Assim, a partir da criticidade, o estudante poderá se desvincular da necessidade de ser aceito, imposta pela sociedade, através da aquisição de produtos e serviços. 
Ainda que os alunos não tenham acertado todas as atividades, consideramos a intervenção positiva no que concerne: i) criticidade mediante a persuasão do mundo capitalista; ii) a estreita relação entre Matemática e Educação Financeira, iii) ao uso de vocabulário apropriado nos debates, tais como: a descobertas de fraudes, desconto, juros simples, juros compostos, inadimplência, endividamento, financiamento, poupança.

Para pesquisas futuras, espera-se que esse trabalho possa ser ampliado para contemplar todos os elementos pertencentes à Matemática Financeira, de modo que estes decorram de maneira crítica e consciente através dos pressupostos da Educação Financeira.

\section{REFERÊNCIAS}

BAUMAN, Zygmunt. Vida para o Consumo: a transformação das pessoas em mercadoria. Rio de Janeiro: Zahar, 2008.

BRASIL. PCN + ENSINO MÉDIO: orientações educacionais complementares aos parâmetros curriculares nacionais - ciências da natureza matemática e suas tecnologias. Brasília: Ministério da Educação (MEC), 2007. Disponível: http://portal.mec.gov.br/seb/arquivos/pdf/CienciasNatureza.pdf. Acesso em 13 de outubro de 2017.

BRASIL. Estratégia Nacional de Educação Financeira (ENEF). Decreto 7397 de 22 de Dezembro de 2010. Disponível em: http://www.planalto.gov.br/ccivil_03/_ato20072010/2010/decreto/d7397.htm. Acesso em: 13 de outubro de 2017.

BRASIL. Banco Central do Brasil (BCB). Caderno de Educação Financeira - Gestão de Finanças Pessoais. Brasília: BCB, 2013. Disponível em: https://www.bcb.gov.br/content/cidadaniafinanceira/documentos_cidadania/Cuidando_do_seu _dinheiro_Gestao_de_Financas_Pessoais/caderno_cidadania_financeira.pdf. Acesso em $15 \mathrm{de}$ dezembro de 2017.

BRASIL. Base Nacional Comum Curricular (BNCC). Brasília: Ministério da Educação (MEC), 2018. Disponível em:

http://basenacionalcomum.mec.gov.br/images/historico/BNCC_EnsinoMedio_embaixa_site_ 110518.pdf. Acesso em: 10 de junho de 2019.

BRASÍLIA. Cartilha de educação financeira para pais. Edições Câmara. 2011. - (Série ações de cidadania: n. 12).

BRAZIL. Implementing the National Strategy, IN: Advancing National Strategies for Financial Education A Joint Publication by Russia's G20 Presidency and the OECD. Disponível em: www.vidaedinheiro.gov.br. 2013. Acesso em: 20 de novembro de 2017.

COOK, Daniel Thomas. Beyond Either/or. Journal of Consumer Culture. p.147-153, 2004. Disponível em: https://doi.org/10.1177/1469540504043678. Acesso em agosto de 2018. 
IEZZI, Gelson; HAZZAN, Samuel. Fundamentos de matemática elementar, 4: sequências, matrizes, determinantes, sistemas: 43 exercícios resolvidos, 407 exercícios propostos com resposta, 302 testes de vestibulares com resposta. $2^{\mathrm{a}}$ ed, São Paulo: Atual, 1977.

IEZZI, Gelson; HAZZAN, Samuel. Fundamentos de matemática elementar, 4: sequências, matrizes, determinantes, sistemas: 43 exercícios resolvidos, 407 exercícios propostos com resposta, 302 testes de vestibulares com resposta. $7^{\mathrm{a}}$ ed. São Paulo: Atual. 2004.

LIMA, Elon Lages; CARVALHO, Paulo Cezar Pinto; WAGNER, Eduardo; MORGADO, Augusto César. A Matemática do Ensino Médio. $6^{\circ}$ ed, Sociedade Brasileira de Matemática, Vol 2. 2006. (Coleção do Professor de Matemática).

PICCINI, Abelardo de Lima. Matemática Financeira: objetiva e aplicada. $9^{\circ}$ ed, São Paulo: Elsevier, 2011.

GODOY, Elenilton Vieira. Currículo, cultura e educação matemática: Uma aproximação possível. Campinas, SP: Papirus, 2015.

RIO DE JANEIRO. Secretaria de Estado de Ciência, Tecnologia e Inovação. Matemática e suas tecnologias: utilizando porcentagens. Fascículo 6, unidade 18, rev, FUNDAÇÃO CECIERJ, CEJA Centro de Educação de Jovens e Adultos, Rio de Janeiro, 2016.

SARAIVA, Karla Schuck. Os sujeitos endividados e a Educação Financeira. Educar em Revista, Curitiba, v. 33, n. 66, p. 157-173, 2017.

SKOVSMOSE, Ole. Cenários para investigação. In: Bolema, nº 14, 2000.

SKOVSMOSE, Ole. Educação Matemática Crítica: a questão da democracia. Campinas, SP: Papirus, 2001.

SKOVSMOSE, Ole. Um convite a Educação Matemática Crítica. Tradução: Orlando Andrade Figueiredo. Campinas, SP: Papirus, 2014.

Recebido em: 15 de janeiro de 2020.

Aprovado em: 16 de abril de 2020. 